\title{
The effects of environmental regulation and technological innovation on green growth: A theoretical analysis
}

\author{
Xuefei $\mathrm{Xu}^{1}$, Lili Wang ${ }^{1, \mathrm{a}}$ and Shang Chen $^{2}$ \\ ${ }^{1}$ Faculty of Humanities and Social Sciences, Dalian University of Technology, Dalian 116024, China \\ ${ }^{2}$ Faculty of Management and Economics, Dalian University of Technology, Dalian116024, China
}

\begin{abstract}
As green growth has attracted a great deal of attention due to the growing concern about the degradation of natural resources and environmental pollution in China, the questions of how to achieve it and which factors drive green growth have become hot topics. Environmental regulation and technological innovation are two main fulcrums in the realization of green growth. However, there is lacking a deeper understanding of the impact of environmental regulation and technological innovation on green growth in a methodological framework. Accordingly, this paper attempts to analyze how these factors affect the implementation of green growth in a model. The findings reveal that (1) in the short term, environmental regulation has inhibited green growth, but has a positive impact on green growth in the long run, (2) technological innovation plays a positive role in green growth improvement, and (3) the causality chain among regulation, technological innovation, and green growth is a typical mediation model. Technological innovation plays an important mediation role in the causal chain. This study not only enriches and deepens theories on green growth, but also successfully implements green growth practices and improve their performance.
\end{abstract}

\section{Introduction}

China has achieved phenomenal growth rates since 1978 's reform and opening-up. As the world's largest developing country, China planned to push the urbanization process as early as 2012, so that to stimulate the economic growth and avoid the middle-income trap. The growth model, however, turned out to be extensive and unsustainable, which favours economy over the environment. Due to the traditional extensive mode of economic growth, the problems of resource depletion and environmental pollution become more and more serious. According to "BP World Energy Statistical Yearbook 2016", China's total energy consumption and net energy consumption accounted for $23 \%$ and $34 \%$ of the world's total respectively in 2015 , resulting in a total of $27 \%$ of the world's carbon dioxide emissions. China has the highest energy consumption and the highest carbon emissions in the developing countries [1].

With the ever-increasing aggravation in resource depletion and environmental pollution, the consensus to transform the original traditional extensive growth mode was reached. However, many developing countries have long considered environmental protection costly and worried that sustainable development might curtail their growth rates. As a result, a new way of green growth

*Corresponding author: ${ }^{\mathrm{a}}$ wangll@dlut.edu.cn was born in the beginning of the 21 st century, which highlighted fostering of economic growth and development, while ensuring that natural assets continue to provide resources and environmental services on which our well-being relies [2].Unlike sustainable development, green growth seeks to encourage economic growth and development in a way that balances concerns about environmental harm with long-term economic growth [3]. Since the introduction of green growth, the concept is widely accepted by many countries, especially developed countries. For example, the UK, Germany and Canada have adopted certain green growth practices in order to achieve economic sustainability and low-carbon development. Chinese government has enacted a series of national strategies aimed at green development as well, such as Law on the Prevention and Control of Environmental Pollution by Solid Waste (2004), Law on Energy Conservation (2007), Circular Economy Promotion Law (2008), Measures for the Public Participation in Environmental Protection (2015), Atmospheric Pollution Prevention and Control Law (2015 Revision) etc. since 2000. Nevertheless, it is not clear whether these policy measures accelerate the coordinated development of both regional economy and regional environment?

New economic growth theory holds that independent research and development can create and accumulate knowledge, promote both products and technical progress, and process innovation, thereby providing a steady stream of motivation and support for sustainable 
economic growth [4].Therefore, enhancing the innovation capability to advance the shift from extensive growth to green development is a pivotal move to realize the medium- and long-term development.

Under the unified analysis framework, this paper aims to contribute to the nascent literature in green growth practices by examining the interactive effects of environmental regulation and technological innovation on green growth performance.

\section{Literature review and hypothesis}

\subsection{Environmental regulation and green growth performance}

As resources and the environment are public goods, there are some limitations to using market mechanisms to solve environmental problems. Therefore, to solve the strategy of the commons, it is important to exert environmental regulations as a powerful deterrence for improving the proportion of cooperators in a group (sustaining cooperation in public goods games) [5]. Environmental regulations include a full range of legal instruments designed by all levels of governments, which are the means to force firms to internalize external costs [6]. Various environmental regulations are used by governments across the world to regulate firms for sustainable development, from technology-forcing standards or market incentives for specific technologies to general economic instruments, such as $\mathrm{CO}_{2}$ taxes and tradable emission permits [7]. However, there is also lack of literature on the relationship between environmental regulations and green growth.

In the short time, environmental regulations adversely affect competitiveness by imposing additional burdens on firms. On the one hand, firms face direct costs induced by pollution control activities. On the other hand, with limited financial budgets, firms will incur opportunity costs by committing resources to comply with regulations, rather than invest in other profitable opportunities [8].

However, in the long time, environmental regulation is the most effective mechanism enabling firms to internalize the influence of their production activity on the natural environment [9].For one thing, environmental regulations place new pressure on firms, and such pressure encourages firms to consider environmental responsibility in their strategy making [10].For another, government policies on environmental regulation are beneficial to energy savings and minimizing cost. Therefore, the pressure of environmental regulations directly causes better performance of green growth. For example, Yi (2013) [11] analyzed clean energy policies in major U.S. cities, and the results showed that national clean energy tools and local climate policies have positive impact on green jobs. Zhao ( 2015) [12]demonstrated that although the effects of different types of environmental regulations on production decisions are different, both command-and-control regulations and market-based environmental regulations promote the firm behaviour shift toward green development, and enhance firm competitiveness. Xie (2017) [13] also drew similar conclusions that reasonable stringency of environmental regulations may enhance rather than lower industrial competitiveness based on China's reality.

Based on the above analysis, we argue that environmental regulation significantly limits corporation behaviour in the short term, but has a positive impact on green growth in the long run.

\subsection{Technological innovation and green growth performance}

According to the theory of "decoupling", green growth means that while achieving economic development and social welfare improvement, resource consumption and environmental damage are reduced, really achieving the decoupling of economy, resources and environment. In this process technological innovation offers a great opportunity for firms to meet customers' demands without harming the environment [14].Technological progress might improve environmental performance both through increased resource efficiency and lower emission intensity in production activities and through the supply new more 'sustainable' products as substitutes to other less efficient products (e.g. energy intensive durable goods).On the other hand, "Isolation mechanisms" created by technological innovation can preserve profit margins and allow firms to gain benefits [15]. Reaping financial benefits of green technological innovation, firms can become more competitive [14]. Therefore, technological innovation can promote the win-win of economic development and environmental protection. Baron and Tang (2011) [16] showed that firms that invest positively in environmental technologies and green product innovation and applications always achieve better environmental and business performance. Similarly, Long et al. (2017) [17] revealed environmental innovation behaviours have significantly positive impact on both economics and environmental performance of Korean-owned firms in China.

As stated above, it is advisable to adopt technological innovative behaviour to promote green growth in China.

\subsection{The mediation role of technological innovation}

Even though technological innovations are essential in order to address green growth, private firms are often not willing to invest in the creation of such technologies because of the "typical spillover effect". As a consequence, market forces cannot bring green innovation to the socially optimal level, and environmental regulations are necessary government interventions to promote technological innovation. Environmental regulations drive enterprises to carry out green innovation by imposing appropriate incentives and restraints, which is parallel with the opinions of Zhang(2018)[18], demonstrating that both 
command-and-control environmental regulations and market-based incentive environmental regulations positively affect green technological innovative behaviour.

In addition, regulations are harmful for private businesses as firms need to spend extra money to deal with regulations in order not to be punished in the short term as mentioned earlier. Nevertheless, Porter and Van Der Linde (1995) [19] argued that properly designed environmental standards can trigger innovation, which may partially or even fully offset the costs of complying with them. Such "innovation offsets", as so called, can lower the net cost of meeting environmental regulations and heighten competitive advantages. Appropriately crafted environmental regulations, therefore, are able to stimulate innovation and enhance competitiveness. With the improvement of environmental innovation, desirable output will increase, and environmental pollutants will decrease, which will improve green growth performance.

Based on the above analysis, we argue that the causality chain among regulation, technological innovation, and green growth is a typical mediation model. Technological innovation plays an important mediation role in the causal chain.

\section{Conclusions and Policy Implications}

This paper draws the conclusions below. First, in the short term, environmental regulations have significantly inhibited green growth, but promoted green growth in the long run. Second, the galvanizing effect of technological innovation is significant on green growth. Third, the promulgation of environmental regulations is conducive to promoting China's regional technological progress. And properly designed environmental regulations may positively affect green growth through motivating technological innovation. The conclusions are in line with Yang and Yang (2015) [20]. Arguably, they also found that the process of eco-innovations in China would be accelerated when a series of energy saving and emissions reduction policies are enforced.

These findings can offer practical implications for managers and environmental policymakers. For companies, managers should regard environmental regulations as positive stimuli. Rather than just oppose legislation and try to slow its passage, a firm can see positive results if it embraces the regulations and can actually use it as the basis of competitive advantage in firms' green growth practices. Whilst others may struggle merely to comply with the regulations and keep their existing operations in order, in the international green competition, the innovative dynamic firm can use it as an opportunity to move into new product markets, move to leaner and greener production processes, which reduce unnecessary energy consumption and material inputs, as well as turning mandatory recycling into a profitable remanufacturing process.

Environmental regulations can encourage green growth in the long term directly and indirectly by the mediating effect of technological innovation.
Consequently, the Chinese government and other developing country governments should insist on environmental regulations to an appropriate extent to seize the opportunity to go "green". If they could make sound environmental regulation policies (such as emissions trading, resource tax, environmental tax, etc) to goad firms' innovation, it is possible to achieve pollution reduction and economic performance increases simultaneously.

\section{Acknowledgement}

This research work is supported by National Social Sciences Fund of China (14BGL124). The authors also would like to thank the editors and reviewers.

\section{References}

1. BP Public limited company. BP World Energy Statistical Yearbook, Beijing,(2016).

2. OECD,Paris: OECD, (2011).

3. D.Popp,Social Science Electronic Publishing, (2012).

4. G.H. Jefferson, H.M. Bai, X J.Guan, X.Y. Yu, Econ. Innov. New Technol., 15, 345-366 (2002).

5. H. Brandt, C. Hauertt, K. Sigmund, Proc. Natl. Acad. Sci. U. S. A.,103, 495-497 (2006).

6. T. Bernauer, S. Engels, D. Kammerer, et al, Polit. Vierteljahr, 39, 323-341 (2006).

7. A. Bergek, C. Berggren, Ecol. Econ,106, 112-123 (2014).

8. W.B. Gray, R.J. Shadbegian, J. Environ. Econ. Manag, 46, 384-402 (2003).

9. M.D. López-Gamero, J.F. Molina-Azorín, E.Claver-Cortés, J.Clean.Prod, 18, 963 -974 (2010).

10. M A.Rugman, A. Verbeke, Strategic Manag. J. 19, 363-375 (1998).

11. H. Yi, Energy Policy, 56, 644-652 (2013).

12. X.L. Zhao, Y. Zhao, S. Zeng, et al, J. Clean. Prod, 86, 311-322 (2015).

13. R.H. Xie, Y.J. Yuan, J.J. Huang, Ecological Economics, 132:104-112 (2017).

14. G.Albort-Morant, A. Leal-Millan, G. Cepeda-Carri on, J. Bus. Res, 69, 4912-4917 (2016).

15. C.H Chang, J. Bus. Ethics, 104, 361-370 (2011).

16. R.A. Baron, J.T. Tang, Bus. Ventur, 26, 49-60 (2011).

17. X.L. Long, Y.Q. Chen, J.G. Du, K.Oh, I. Han, Energy Policy, 107: 131-137 (2017).

18. Y. Zhang, J. Wang, Y. Xue, et al, J. Clean. Prod, 188, 763-773 (2018). 
19. M.E. Porter, C.V.D. Linde, J. Econ. Perspect, 9 ,97-118 (1995).

20. F. Yang, M. Yang, Eur. J. Operational Res, 247 , 1003-1012 (2015). 